\title{
The Study of Synthesis, Accumulation and Release Processes of Atrial and Brain Natriuretic Peptides in Experimental Renovascular Hypertension
}

DOI: $10.17691 / \mathrm{stm} 2015.7 .2 .04$

Received November 10, 2014

M.V. Galkina, PhD, Senior Researcher, Electron Microscopy Unit, Central Scientific Research Laboratory;

O.S. Baskina, PhD, Senior Researcher, Morphology Department, Central Scientific Research Laboratory;

M.L. Bugrova, PhD, Associate Professor, Head of Electron Microscopy Unit, Central Scientific Research Laboratory

Nizhny Novgorod State Medical Academy, 10/1 Minin and Pozharsky Square, Nizhny Novgorod,

603005, Russian Federation

The aim of the investigation was to study the dynamics of synthesis, accumulation and release processes of atrial (ANP) and brain (BNP) natriuretic peptides on day 60 of experimental renovascular hypertension.

Materials and Methods. The experiments were carried put on white non-pedigree male rats. We studied renovascular hypertension using a two-kidney model with the left renal artery ligation. Arterial pressure (AP) was measured via caudal artery using an invasive technique. We analyzed left ventricular cardiac myocyte areas by light optics. Electron microscopic investigation was applied to study the left ventricular and right atrial tissue samples. ANP and BNP accumulation and release processes were assessed using a quantitative analysis of immunolabeled granules of atrial myocytes (A-type, "mature, storing", and B-type, "dissolving") under the transmission electron microscope. We performed a morphometric analysis of morphological types of the left ventricular and right atrial mitochondria.

Results. The number of granules containing ANP and BNP in atrial myocytes on day 60 after the left renal artery ligation in rats was found to be no significantly different from that in the intact group. We revealed AP decrease up to the initial level. ANP and BNP content in atrial myocytes and AP recovered against the background of cardiac myocyte hypertrophy, mitochondrial de-energization and destructive changes in microcirculatory bloodstream.

Conclusion. In a long-term period of experimental renovascular hypertension, ANP and BNP have a positive effect on AP level falling up to the initial one due to ANP and BNP release on day 30 of the experiment. The efficiency of natriuretic peptides acting as a regulatory component in primary hypertension formation depends on arterial hypertension genesis.

Key words: atrial natriuretic peptide; brain natriuretic peptide; renovascular hypertension.

Atrial (ANP) and brain (BNP) natriuretic peptides fall under a group of hormones participating in the regulation of electrolyte balance and hemodynamics, and aim at arterial pressure (AP) reduction [1-6]. In different cardiovascular pathologies accompanied by elevated AP, high concentrations of natriuretic peptides do not have an antihypertensive effect. Insufficient ANP and BNP synthesis is supposed [7] to be one of the causes of arterial hypertension: there is an increase of their concentration in blood plasma, and decrease - in atria. Another reason of inefficiency of natriuretic peptides is thought to be decreased density of A- and B-type receptors on the surface of target-organs, and disband with guanylate cyclase [8]. There is one more explanation of the increased number of C-type receptors, the activation of which results in enzymatic breakdown of ANP and BNP by neutral endopeptidaze [9]. Such ambiguity in hypotheses can be related to different methodological approaches: some researchers study plasma using enzyme immunoassay [10], others use myocardial blot analysis [11], and others - morphometry of atrial myocyte granules [12]. The combination of electron microscopy, immunocytochemistry, a quantitative analysis of different types of granules of secretory cardiomyocytes (CMC) and AP level control enable to explain the processes proceeding in rats with simulated pathological condition [13].

One of common cardiovascular pathologies is

For contacts: Galkina Maria Vladimirovna, e-mail: maryrax82@gmail.com 
renovascular hypertension due to ischemic kidney disease. Generally, in a natural course of the disease and the absence of adequate treatment, about $70 \%$ patients die of complications (brain stroke, myocardial infarction, renal failure) within the next 5 years [14-16]. Renal artery is generally ligated to induce vasorenal hypertension to study its pathogenesis $[17,18]$. In our previous studies on this model [19] we showed that stable arterial hypertension developed by day 30 . In elevated AP there was reduced synthesis and increased release of natriuretic peptides in rat atrial myocytes in the periods under study. The findings can be interpreted controversially, since there is a hypothesis [20] that natriuretic peptides themselves serve as a regulatory component of primary hypotension formation. Thus, to understand the processes of renovascular hypertension pathogenesis, we are to study the changes in the body in a long-term period of the experiment (60 days).

The aim of the investigation was to study the dynamics of synthesis, accumulation and release processes of atrial and brain natriuretic peptides on day 60 of experimental renovascular hypertension using the morphometry of granules of secretory cardiomyocytes.

Materials and Methods. The experiments were carried out in accordance with the laboratory routine rules, on 15 non-pedigree male rats weighing 180 $220 \mathrm{~g}$. The work was performed in full accordance with the Ethical Principles of the European Convention for Protection of Vertebrate Animals Used with Experimental and Other Scientific Purposes (the Convention took place in Strasbourg on 18.03.1986 and was confirmed in Strasbourg on 15.06.2006). Vasorenal hypertension was studied on a two-kidney model with the left renal artery ligation [21]. AP was measured invasively via caudal artery using a pressure probe MPX5050DP (Motorola, USA). The signal obtained was analyzed using a software system PowerGraph V.2.0.
The left ventricular tissue samples of intact and experimental animals were analyzed by means of electron microscopy (on day 60 after the left renal artery ligation) [22]. ANP and BNP cell localization was revealed by immunocytochemistry on ultrathin sections using polyclonal antibodies to ANP - Rabbit antiAtrial Natriuretic Factor (1-28) (rat) (Peninsula Lab. Inc., Bachem, USA) and BNP - Rabbit anti-Brain Natriuretic Peptide-32 (Rat) Serum (Peninsula Lab. Inc., Bachem, USA). Protein-A/Gold (15 nm) (EM Grade, Electron Microscopy Sciences, USA) were used as second antibodies. The sections were uranyl acetate and lead citrate contrasted and analyzed under an electron microscope Morgagni 268D (FEl, USA). A quantitative analysis of the two types of granules with peptides in atrial CMC (A-type, 'mature, storing' and B-type, 'dissolving') was performed by calculating in fields of vision $(38 \times 38 \mu \mathrm{m})$ $[21,23]$. We performed a morphometric analysis of morphological types of $\mathrm{CMC}$ mitochondria of the right atrium and the left ventricle in fields of vision $(38 \times 38 \mu \mathrm{m})$. In accordance with one of main classifications [24] we distinguished three types of mitochondria: mitochondria in energized condition (physiological norm), orthodox mitochondria (swollen, matrix clarification and cristae desorientation) and vacuolated mitochondria (with large intramitochondrial vacuoles containing membrane structures resembling myelin-like bodies).

We performed light-optical study of the left ventricular tissues in intact and experimental rats 60 days after the left renal artery ligation. The samples were formol fixed and embedded in paraffin [24]. 5-7 $\mu \mathrm{m}$ sections obtained on a microtome SM 2000R (Leica, Austria) were hematoxylin and eosin stained using a light microscope Eclips 80i (Nikon, Japan) and a program NIS-Elements BR 4.00.02. The area of CMC $\left(\mu \mathrm{m}^{2}\right)$ was measured at $\times 40$.

The findings were statistically processed using Statistica 10.0 and Mann-Whitney U-test $(p<0.05)$.

Results. Cardiomyocytes of experimental rats were found to have ANP- and BNP-immunoreactive materials in granules of both types. It should be noted that all granules were marked by both antibodies, i.e. they contained both ANP, and BNP. A morphometric analysis of secretory $\mathrm{CMC}$ of the right atrium 60 days after the left renal artery ligation showed that the number of A- and B-type granules, and the total number of granules did not differ significantly from those of intact rats (Figure 1).

AP level by the day 60 of the experiment was no different significantly from its initial level (Figure 2).

Light-optical study of the left ventricular myocardium revealed $\mathrm{CMC}$

after the left renal artery ligation in rats (according to Mann-Whitney U-test) 
Figure 2. The change of mean AP within 60 days after the left renal artery ligation in rats (according to Mann-Whitney U-test)

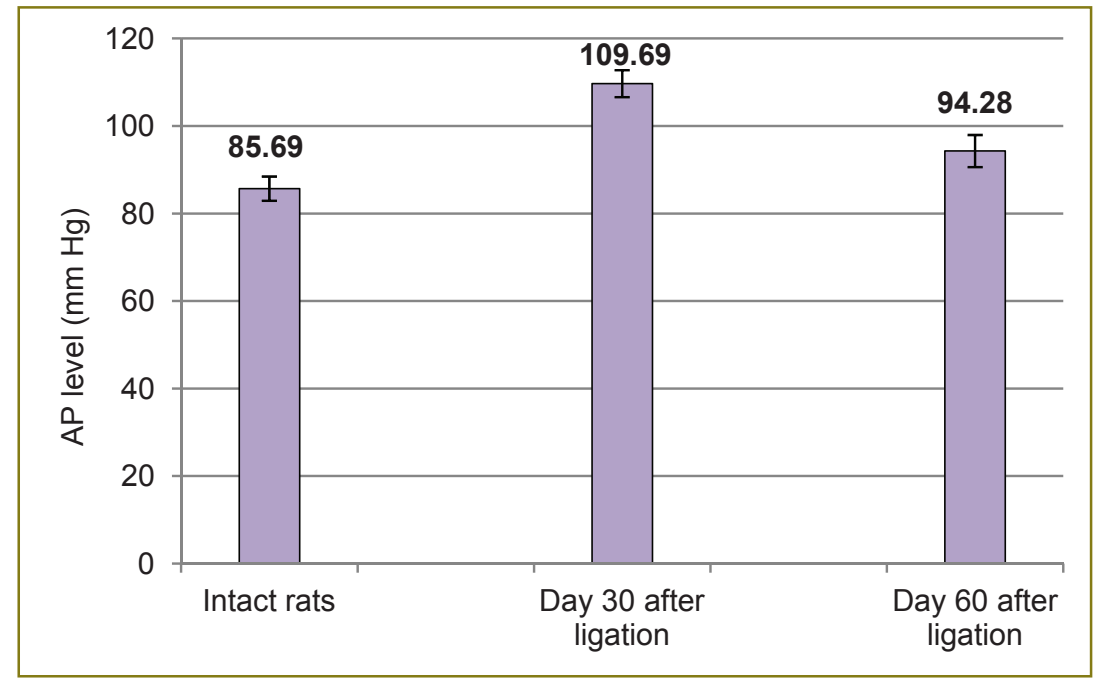

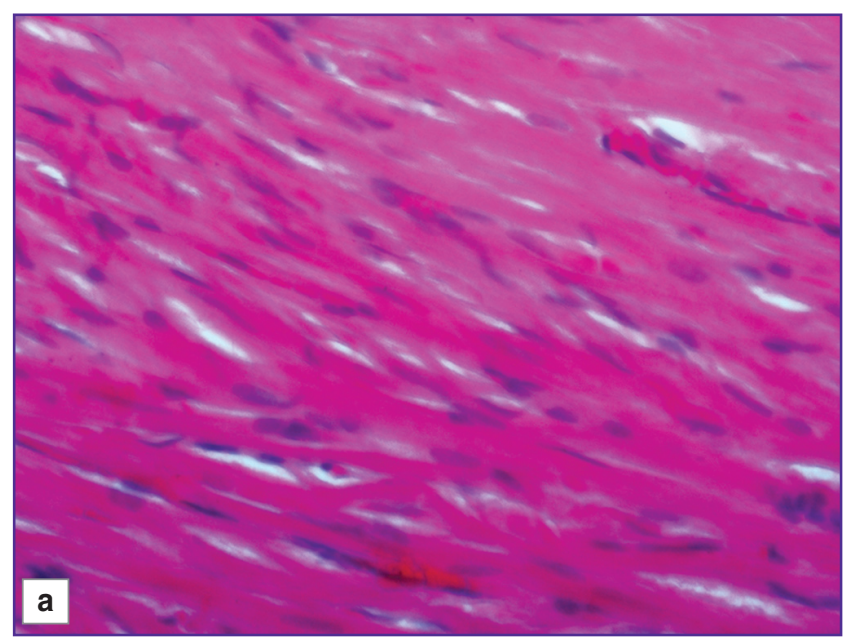

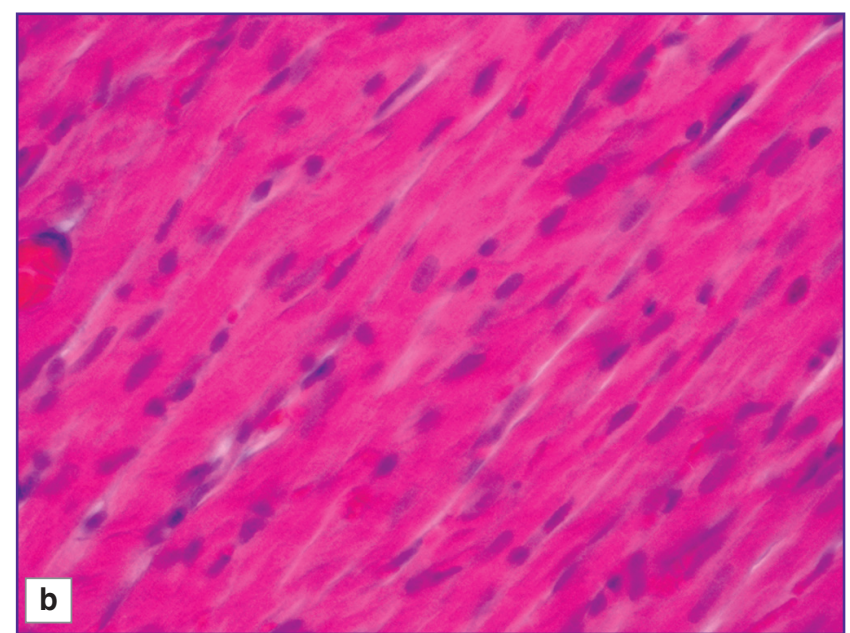

Figure 3. Left ventricular myocardial structure; ocular lens $\times 10$, objective lens $\times 40$; hematoxylin and eosin staining: (a) in an intact rat; (b) in a rat 60 days after the left renal artery ligation

hypertrophy (Figure 3). A morphometric analysis showed the significant increase of CMC area: by $61 \%$ compared to intact animals, and by $6 \%$ - with reference to the day 30 of the experiment (Figure 4).

The electron microscopic analysis of the left ventricle and the right atrium of experimental animals revealed similar mosaic changes of CMC: the nuclei of some cells contained a nucleolus and euchromatin; while in other cells the nuclei had no nucleoli, and there was karyolemma invagination, and heterochromatin, the perinuclear space being totally extended (Figure 5). All myocytes had altered mitochondrial structure: the number of mitochondria in the condition of physiological norm decreased by nearly half; while the number of orthodox mitochondria and vacuolated mitochondria increased (Figure 6).

Myofibrils were relaxed. Some CMC had the zones of microfibrillar overcontraction. Most myocytes were found to have extended cisterns of sarcoplasmic reticulum.

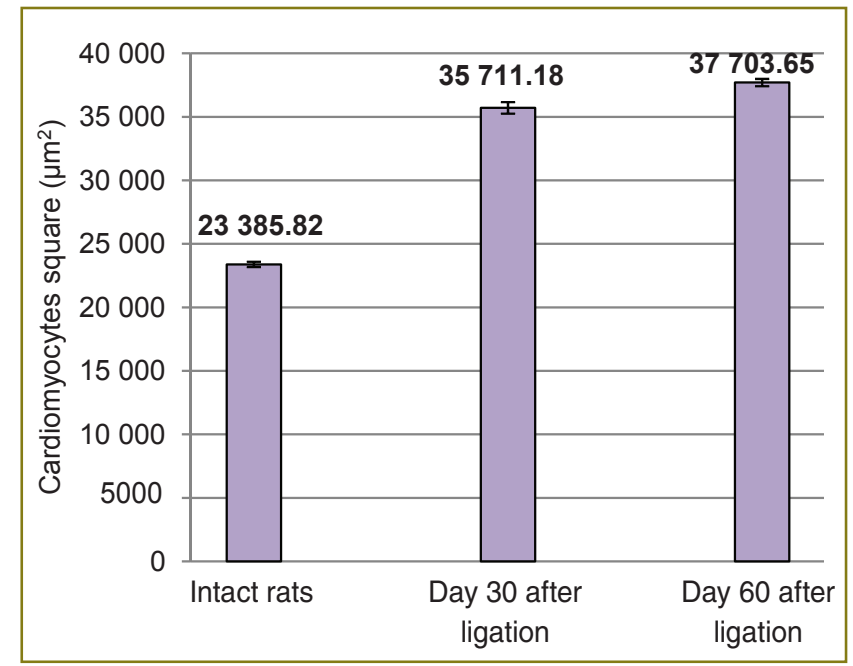

Figure 4. The change of cardiomyocytes square within 60 days after the left renal artery ligation in rats (according to MannWhitney U-test) 


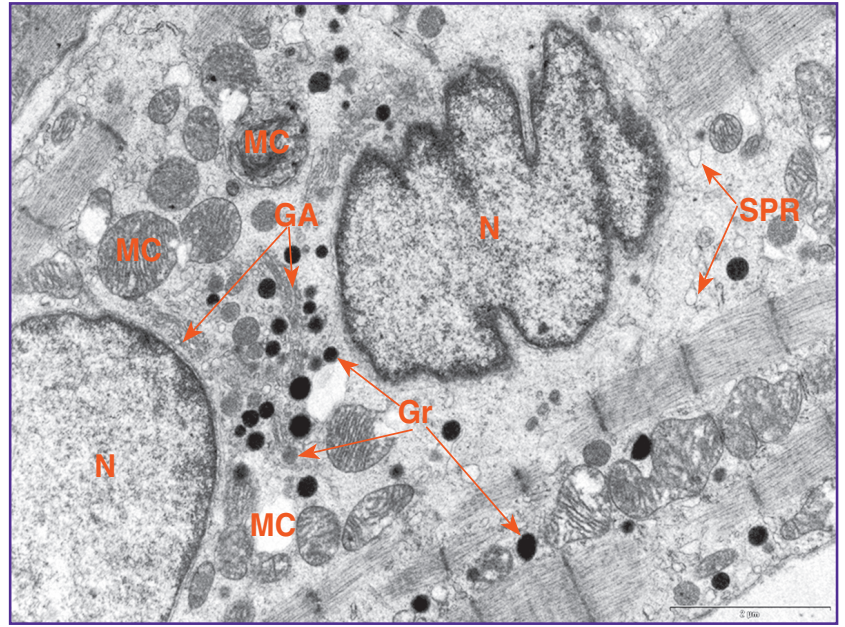

Figure 5. The right atrial cardiomyocyte ultrastructure 60 days after the left renal artery ligation. GA: a developed Golgi apparatus; Gr: granules; MC: mitochondria; SPR: extended sarcoplasmic reticulum; N: nucleus; $\times 8900$

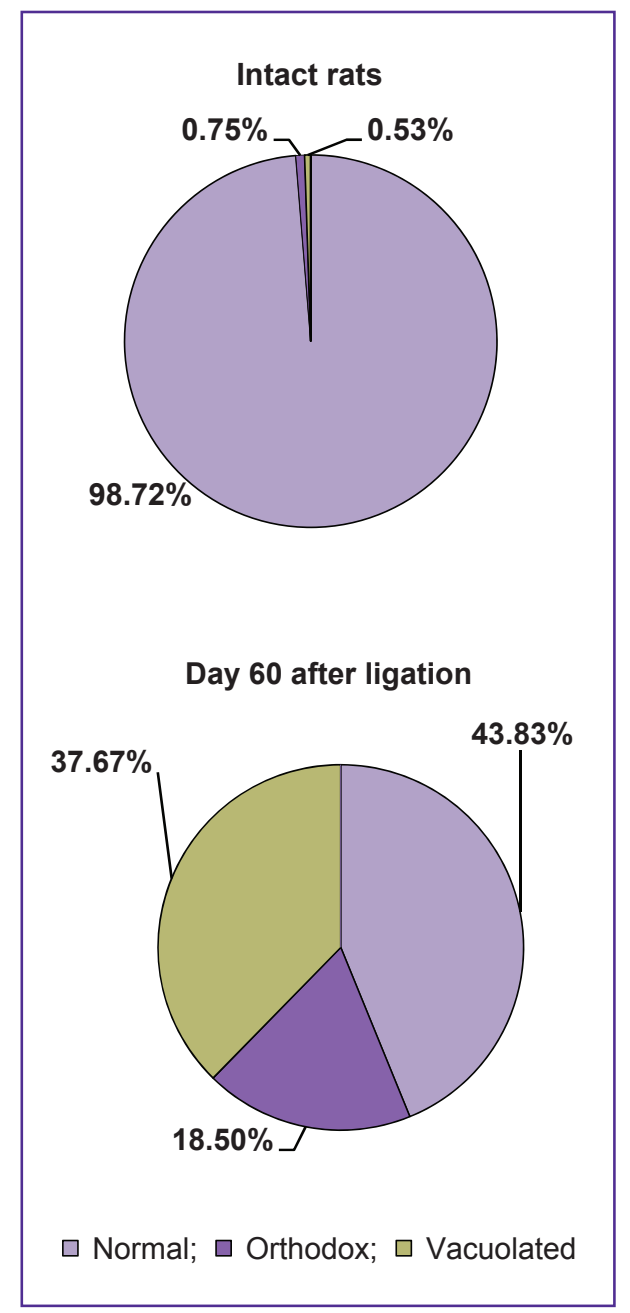

Figure 6. The change of percentage composition of morphological types of mitochondria 60 days after the left renal artery ligation

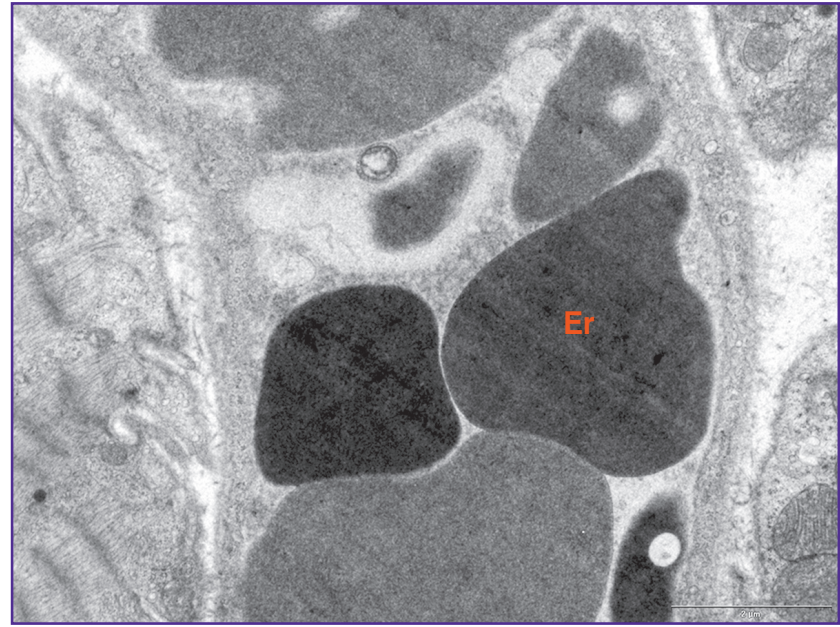

Figure 7. A capillary with aggregated erythrocytes; $\times 8900$. Er: erythrocytes

Golgi apparatus was well developed, and there was hyperplasia and hypertrophy of its components, which were located not only around the nucleus but also on the periphery of atrial CMC (See Figure 5). We found the areas with sarcolemma blurring and decondensation ground substance of basal membrane. The changes were associated with intercellular edema. There was intercalated disc divergence. Microvasculature was found to have destructive changes: the integrity of endothelial wall was damaged, and erythrocyte released into interstitial space, the capillaries having aggregated red blood cells and platelets, there being pericapillary edema (Figure 7).

Discussion. Intracellular mechanisms of synthesis, accumulation and release of natriuretic peptides have not been studied thoroughly due to technical difficulties of their identification and visualization [25]. The use of a quantitative method to calculate immunolabeled granules of secretory $\mathrm{CMC}$, as well as morphological and physiological techniques enables to obtain complete information to study natriuretic peptides. Considering the data obtained ion day 30 of the experiment [19], the follow up study enables to reveal the dynamics of changes in rat body in a long-term period. No significant differences of numeric values of A- and B-type granules and AP level on day 60 of the experiment compared to the intact animals indicated the recovery of these parameters to initial ones during the period under study. It should be noted that against the background of the findings we revealed marked destructive changes in the left ventricular and the right atrial CMC. The reports in literature [26] show that mitochondrial swelling is of adaptive nature. However, it contributes to their functioning till spatial relationships of structural elements are preserved. Intense mitochondrial swelling indicated 
impaired effective functioning - de-energization. The observed changes of mitochondria, sarcolemma, as well as extended cisterns of sarcoplasmic reticulum are common features of calcium damage of CMC.

Our previous studies $[19,21]$ showed fast release of ANP and BNP from cells on day 30 after the left renal artery ligation against elevated $\mathrm{AP}$ and $\mathrm{CMC}$ hypertrophy (See Figure 2). According to Wang et al. [27], CMC hypertrophy is related to ING3 expression (inhibitor of growth family, member 3 ), the activation of which results in the increase of plasma level of ANP and BNP after abdominal aortic compression in rats. Other researchers [20] have reported that left ventricular CMC hypertrophy developing in 6-month ISIAH rats with inherited stress induced arterial hypertension against the background of high AP is a compensatory reaction on hemodynamic disorders due to peripheral resistance increase.

Natriuretic peptides were likely to promote AP level recovery by day 60 , and thus, were essential components in a chain of complex compensatory reactions aimed at hypertension inhibition. Protective properties of peptides were demonstrated in the experiment on dogs with left ventricular failure induced by cardiac stimulation: the use of neutral endopeptidase inhibitor and ANP administration resulted in natriuresis increase and cyclic guanosine monophosphate formation in kidneys [7]. Clinical studies [28] showed that intracoronal BNP administration reduces pressure in the pulmonary artery, left ventricular end diastolic pressure and mean AP.

The discovered recovery of granules with ANP and BNP, and AP up to an initial level on day 60 of experimental vasorenal hypertension is not consistent with the findings showing the decrease of natriuretic peptides in atria of patients with progressive arterial hypertension [29, 30]. The authors of the study [25] have indicated the accumulation of a great number of mature granules and inhibited release of such peptides in old hypertensive ISIAH rats with inherited stress induced arterial hypertension against the background of persisting elevated pressure. The efficiency or inefficiency of natriuretic peptides acting as a regulatory component in primary hypertension formation is curtain to depend on arterial hypertension genesis. Application of a complex of advanced techniques enabled to reveal a positive effect of ANP and BNP on AP in a long-term period (day 60).

Thus, the recovery of synthetic activity of natriuretic peptides and AP recovery to its initial level proceed against the background of intensity of intracellular regulation system under adaptation to renovascular hypertension as evidenced by marked ultrastructural changes of the right atrial and left ventricular cardiomyocytes and hemocapillaries.

Conclusion. In vivo study carried out using a quantitative analysis of atrial cardiomyocyte granules containing atrial and brain natriuretic peptides enables to conclude that in a long-term period of experimental renovascular hypertension (on day 60) atrial and brain natriuretic peptides have a positive effect on arterial pressure level falling up to the initial one due to peptides release on day 30 of the experiment. The efficiency of natriuretic peptides acting as a regulatory component in primary hypertension formation depends on arterial hypertension genesis.

Study Funding. The research was carried out within the frame of departmental research work of Ministry of Health of the Russian Federation 2012-2016 "Regulation mechanisms of physiological functions in experimental body state".

Conflict of Interests. The authors have no conflicts of interest to declare.

\section{References}

1. Baertschi A.J., Monnier D., Schmidt U., Levitan E.S., Fakan S., Roatti A. Acid prohormone sequence determines size, shape, and docking of secretory vesicles in atrial myocytes. Circ Res 2001; 89(3): E23-E29, http://dx.doi. org/10.1161/hh1501.095715.

2. Marei H.E. Fine structural and immunohistochemical localization of cardiac hormones (ANP) in right atrium and hypothalamus if the white rat. Eur $J$ Morphol 2002; 40: 37-41, http://dx.doi.org/10.1076/ejom.40.1.0037.

3. Krylova M.I. Chromogranin A: immunocytochemical localization in secretory granules of frog atrial cardiomyocytes. Tsitologiya 2007; 49(7): 538-543.

4. Rakhcheeva M.V., Bugrova M.L., Mukhina I.V., Zhabereva A.S. Atrial natriuratic peptide and experimental vasorenal hypertension in rats. Patologicheskaya fiziologiya $i$ eksperimental'naya terapiya 2010; 4: 31-33.

5. de Bold A.J. Thirty years of research on atrial natriuretic factor: historical background and emerging concepts. Can J Pharmacol 2011; 89: 527-531, http://dx.doi.org/10.1139/ y11-019.

6. Ogawa T., de Bold A. The heart as an endocrine organ. Endocr Connect 2014; 3(2): R31-R44, http://dx.doi. org/10.1530/EC-14-0012.

7. Gurevitch M.A., Mravyan S.R., Veselova T.E. Significance of the system of atrial natriuretic peptides in heart failure and hypertension. Kardiologiia 2003; 9: 81-87.

8. Liu R.T., Xiao H.L., Guo H.L., Qui D.G., Yin H.H., Wang Z.R. Expression of A-type atrial natriuretic peptide receptor in the kidneys of renovascular hypertension rats and its implication. Sichuan Da Xue Xue Bao Yi Xue Ban 2005; 36(6): 776-778.

9. Irzmański R., Barylski M., Banach M., Piechota M., Kowalski J., Cierniewski C., Pawlicki L. The concentration of atrial and brain natriuretic peptide in patients with idiopathic hypertension. Med Sci Monit 2007; 13(10): CR449-CR456.

10. Saliba Y., Chouery E., Mégarbané A., Jabbour H., Farès N. Microalbuminuria versus brain natriuretic peptide in cardiac hypertrophy of hypertensive rats. Physiol Res 2010; 59(6): 871-880.

11. Sun Y., Deng T., Lu N., Yan M., Zheng X. B-type natriuretic peptide protects cardiomyocytes at reperfusion via mitochondrial calcium uniporter. Biomed Pharmacother 2010; 64(3): 170-176, http://dx.doi.org/10.1016/j.biopha. 2009.09.024. 
12. Maksimov V.F., Korostyshevskaya I.M., Kurganov S.A., Markel A.L., Rudenko N.S., Jakobson G.S. Changes of right atrial myoendocrine cells during hypertension and after arterial pressure decrease. Tsitologiya 2014; 56(10): 725-734.

13. Bugrova M.L., Abrosimov D.A., Yakovleva E.I., Baskina O.S., Ermolin I.L. The study on atrial natriuretic peptide of cardiomyocytes in a remote postperfusion period in experiment. Sovremennye tehnologii v medicine 2013; 5(4): 39-44.

14. Mussalo H. Cardiovascular autonomic regulation in patients with sustained hypertension of different etiology and severity. Doctoral dissertation. Kuopio University Publications; 2003.

15. Kawarada O., Yokoi Y., Morioka N., Takemoto K. Renal artery stenosis in cardio- and cerebrovascular disease: renal duplex ultrasonography as an initial screening examination. Circ J 2007; 71(12): 1942-1947, http://dx.doi.org/10.1253/ circj.71.1942.

16. Mukhin N.A., Fomin V.V., Moiseev S.V., et al. Ischemic renal disease (atherosclerotic renovascular hypertension), a clinical variant of disseminated atherosclerosis and a cause of chronic renal insufficiency. Vestnik RAMN 2008; 11: 24-33.

17. Kharin S.N., Krandycheva V.V. Renal artery stenosis technique to model renovascular hypertension in rats. Bulleten' eksperimental'noj biologii i mediciny 2004; 7: 118-120.

18. Rakhcheeva M.V. Rol' predserdnogo i mozgovogo natriyureticheskikh peptidov $v$ regulyatsii arterial'nogo davleniya pri vazorenal'noy gipertenzii u krys. Avtoref. dis. ... kand. biol. nauk [The role of atrial and brain natriuretic pepties in arterial pressure regulation in renovascular hypertension in rats. Abstract for the Dissertation of Candidate of Biological Sciences]. Moscow; 2009.

19. Rakhcheeva M.V., Bugrova M.L., Mukhina I.V., Zhabereva A.S. The role of atrial natriuretic peptide in regulation of arterial pressure in two kidney one renal artery ligation in rats. Vestnik Nizhegorodskogo gosudarstvennogo universiteta im. N.I. Lobachevskogo 2009; 6(1): 132-136.

20. Maksimov V.F., Korostyshevskaya I.M., Markel A.L., Filyushina E.E., Jakobson G.S. Cardiac natriuretic peptides and hypertension: experimental study. Vestnik RAMN 2013; 1: 4-9.
21. Rakhcheeva M.V., Bugrova M.L. Reproportion of A- and $B$-type granules containing atrial and brain natriuretic peptides in rat atrial myocytes under renovascular hypertension. Tsitologiya 2010; 8: 629-633.

22. Mikroskopicheskaya tekhnika [Microscopy technique]. Pod red. Sarkisova D.S., Perova Yu.L. [Sarkisov D.S., Perov Yu.L. (editors)]. Moscow: Meditsina; 1996; 544 p.

23. Bugrova M.L., Yakovleva E.I., Abrosimov D.A. The relationship of synthesis intensity, accumulation and secretion of natriuretic peptide of atrial myocytes with cardiac rhythm regulation in rats in early postperfusion period. Sovremennye tehnologii v medicine 2012; 3: 26-30.

24. Sudarikova Yu.V., Bakeeva L.E., Tsyplenkova V.G. Energy dependent alterations of human cardiomyocytes mitochondria ultrastructure in alcoholic heart disease. Arhiv patologii 1999; 2: 15-20.

25. Korostyshevskaya I.M., Maksimov V.F., Kurganov S.A. Ultrastructural estimation facilities of atrial cardiomyocyte secretory activity. Tsitologiya 2013; 55(8): 539-547.

26. Sperelakis N., Forbs M.S. Ul'trastruktura miokarda mlekopitayushchikh. V kn.: Fiziologiya i patofiziologiya serdtsa. Tom I [Mammalian myocardial ultrastructure. In: Cardiac physiology and pathophysiology. Vol. I]. Moscow; 1990; p. 15-64.

27. Wang J., Liu Z., Feng X., Gao S., Xu S., Liu P. Tumor suppressor gene ING3 induces cardiomyocyte hypertrophy via inhibition of AMPK and activation of p38 MAPK signaling. Arch Biochem Biophys 2014; 562: 22-30, http://dx.doi.org/10.1016/ j.abb.2014.08.007.

28. Bugrimova M.A., Savina N.M., Vanieva O.S., Sidorenko B.A. Brain natriuretic peptide as marker and factor of prognosis in chronic heart failure. Kardiologiia 2006; 1: 51-57.

29. Langenickel T., Pagel I., Höhnel K., Dietz R., Willenbrock R. Differential regulation of cardiac ANP and BNP mRNA in different stages of experimental heart failure. Amer J Physiol Heart Circ Physiol 2000; 278(5): H1500-H1506.

30. Vesely D.L. Discovery of new cardiovascular hormones for the treatment of congestive heart failure. Cardiovasc Hematol Disord Targets 2007; 7(1): 47-62, http://dx.doi.org/ 10.2174/187152907780059128\#sthash.aO3kug5A.dpuf. 